\title{
Correction to: Axially aligned electrically conducting biodegradable nanofibers for neural regeneration
}

\author{
Anuradha Subramanian $^{1} \cdot$ Uma Maheswari Krishnan ${ }^{1} \cdot$ Swaminathan Sethuraman $^{1}$
}

Published online: 13 May 2019

(c) Springer Science+Business Media, LLC, part of Springer Nature 2019

\section{Correction to:}

\author{
Journal of Materials Science: Materials \\ in Medicine (2012) 23:1797-1809 \\ https://doi.org/10.1007/s10856-012-4654-y
}

The original version of this article unfortunately contained a mistake. The presentation of Fig. 2e was incorrect. The corrected version of Fig. 2E1 is given below.

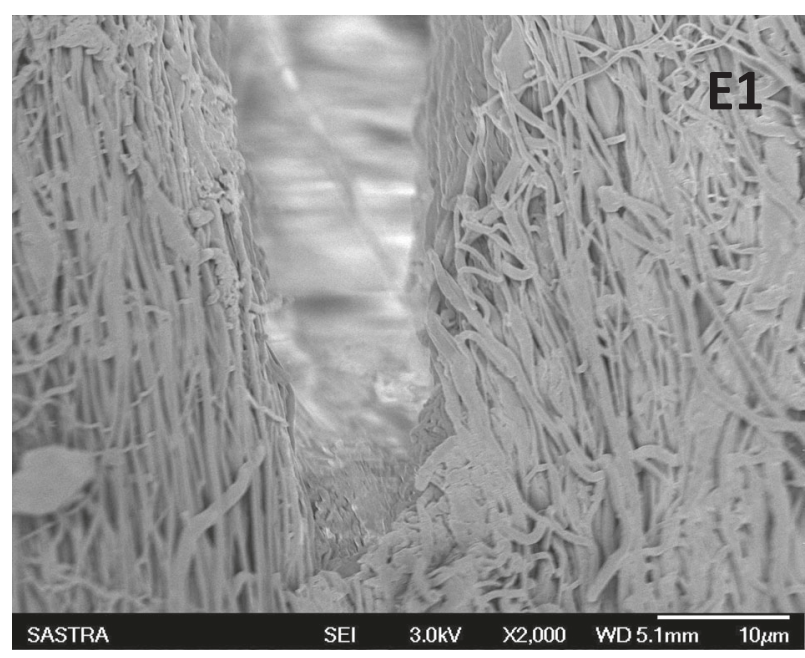

Fig. 2 Scanning electron micrograph showing the orientation of fiber angle of PLGA-PHT nanofiber at rotation speed: 2,000 rpm 